\title{
A crítica inflexionista das análises do fordismo brasileiro da década de 1980
}

Leandro Theodoro Guedes ${ }^{1}$

\section{Resumo:}

Procura-se mostrar as imprecisões do conceito de fordismo, difundido pela Escola da Regulação, e reverberado por estudiosos do processo de trabalho no Brasil, para descrever um processo de trabalho específico e suas mudanças. Foi visto que a análise de um caso concreto da indústria automotriz no Brasil deixou de explicitar as mudanças em curso, por privilegiar os aspectos mais abstratos deste conceito. Entende-se que uma alternativa para as lacunas desta análise está nas categorias marxianas, especialmente (manufatura e grande indústria).

Palavras-chave: processo de trabalho; regulacionismo; fordismo.

\section{The inflexionist critique of Brazilian fordism analysis of the 1980 decade}

\begin{abstract}
:
We aim to show the inaccuracies of the concept of fordism, diffused by the School of Regulation, and reverberated by scholars of the work process in Brazil, to demonstrate a specific work process and its changes. It was seen that the analysis of a concrete case in automotive industry in Brazil failed to make explicit the changes that were in progress, as they favoured the more abstract aspects of this concept. It is understood that an alternative to the gaps in this analysis is in the Marxian categories, especially (manufacture and large industry).
\end{abstract}

Key words: labour process; regulationism; Fordism.

\section{Introdução}

A chamada Escola Francesa da Regulação exerceu uma importância definitiva na evolução dos estudos acerca do processo de trabalho, ao menos nos últimos 40 anos. Basta recordar a ampla difusão da utilização da categoria do fordismo como fundamento explicativo para toda conjuntura macroeconômica do período entre o fim da Segunda Guerra Mundial e a década de 1970, como a conjunção de produção em massa, linhas de montagem semiautomáticas, integração entre os departamentos 1 e 2 e padrão salarial (regime de acumulação). Destacam-se autores como

1 Mestrando pela Universidade Federal de Juiz de Fora (UFJF). E-mail: ltheodoroguedes@yahoo.com. 
Aglietta, Coriat, Boyer, Lipietz, dentre outros. Por outro lado, em relação ao processo de trabalho, especificamente, é possível considerar, como outra forma de compreensão, a corrente analítica que parte das categorias marxianas mesmo (cooperação simples, manufatura e grande indústria), entendendo-as como relações sociais de produção. Esta corrente desenvolve as análises procurando considerar as diferenças setoriais, o que impede uma generalização, como ocorre na teoria da regulação.

No Brasil, a Escola Regulacionista, não passou incólume, iluminando uma série de debates. Estes principais trabalhos, que averiguaram a caracterização do fordismo brasileiro estão mais concentrados entre as décadas de 1980 e 1990, investigando não somente a questão do processo de trabalho (SCHMITZ; CARVALHO, 1989), mas também aqueles aspectos contidos na análise de Aglietta (CORIAT; SABOIA, 1989; FERREIRA, 1993; FERREIRA; FERREIRA, 2015), levando-se em conta tal acepção mais ampla do fordismo e a evolução industrial no setor automotriz. Embora os textos estejam datados, não há como ignorar a influência do debate que parte do fordismo (e deságua em desdobramentos como o pós-fordismo) para explicar as mudanças que levaram a questões mais contemporâneas (ANTUNES, 2018; ALVES, 2011; FARIA, 2017). Daí a importância dos autores brasileiros mais ligados ao regulacionismo: eles desenvolveram estudos que investigaram a anatomia de um fordismo brasileiro na realidade concreta.

O propósito deste trabalho é demonstrar como o vínculo dos autores ao fordismo, como categoria explicativa da evolução das relações sociais de produção, faz com que o movimento de mudança do princípio subjetivo para o princípio objetivo, a inflexão da base técnica que modifica o processo de trabalho, seja perdido de vista. Ao invés de uma acentuação do fordismo, o caso concreto indica a caminhada em direção à sua destruição. O apego ao fordismo faz com que se concentre mais nos elementos que igualam relações sociais de produção distintas, do que as distingam propriamente. Será feita uma análise dos textos desses autores do regulacionismo brasileiro para mostrar que as informações apresentadas pelos autores podem ser melhor analisadas a partir das categorias marxianas: manufatura e grande indústria que, como exaustivamente tratado por Moraes Neto $(1987$; 1988; 2003) demonstram a inflexão da base do processo de trabalho centrada na divisão do trabalho (princípio subjetivo) para a base centrada no sistema de máquinas (princípio objetivo). Como exemplo de estudos baseados nessas análises, tem-se o estudo de Kabat (2008) que pôde verificar a inflexão no setor de calçados argentino. Pesquisas como esta, evidenciam a importância da análise setorial e que respeita os diferentes graus de desenvolvimento industrial entre os ramos da economia. 
Na sequência do texto, serão apresentadas as bases do debate do fordismo para a teoria regulacionista e a alternativa para a compreensão das mudanças do processo de trabalho, encontrada em Marx (podendo ser denominada abordagem inflexionista), e, na sequência serão trazidos os dados analisados pelos autores em debate, evidenciando como neles estão contidos aspectos da inflexão do setor automotivo brasileiro para a grande indústria, ao invés de uma acentuação do fordismo.

\section{A inadequação do fordismo e contribuições do inflexionismo para a análise do processo de trabalho}

$\mathrm{Na}$ abordagem regulacionista, o mote principal é a tentativa de explicar os ciclos econômicos do capitalismo a partir da combinação de vários fatores atuando em conjunto. Destes ciclos, destacou-se, nas análises, aquele compreendido entre o final da II Guerra Mundial e a década de 1970, no qual, para os autores, ocorreu uma ampla difusão do fordismo. A análise do problema se concentra na ocorrência de uma mudança no processo de trabalho, que no caso está representada pela produção em massa (CORIAT, 1982; AGLIETTA, 2011), que desencadeia um novo patamar de produtividade. Este novo patamar precisa ter alguma correspondência na esfera do consumo, passando a haver uma política salarial corroborada pela atuação do estado através de políticas que contribuam, ainda que indiretamente, para ao aumento da renda dos trabalhadores. E assim, este ciclo evolui até a exaustão. Como descreve Gounet, em sua crítica a esta corrente:

O sistema taylorista é eficaz porque racionaliza o trabalho individual, permitindo uma produção em massa, em nível sem igual até então. Porém para que ele funcione efetivamente é preciso existir uma demanda capaz de absorver o aumento da produção - em outras palavras, um consumo em massa. $\mathrm{O}$ sistema não proporciona essa condição espontaneamente (GOUNET, 1999, pp. 59-60).

Autores como Lipietz (1989) levam isso ainda mais adiante considerando as diferenças entre os países. Classificando a formulação básica de Aglietta como fordismo central, o autor chama a atenção para as experiências do hemisfério sul, que desenvolveu um fordismo restrito "uma tentativa de industrialização segundo a tecnologia e o modelo de consumo fordianos, ainda que sem as condições sociais, seja no referente ao processo de trabalho, seja no referente à norma de consumo das massas” (LIPIETZ, 1989, p. 310). Nessa discussão, ele insere variantes como taylorismo primitivo (mais comum a países do sudeste asiático que, concentrados na produção de vestuário e componentes eletrônicos, possuíam uma matriz produtiva ainda muito taylorizada) e fordismo 
periférico (como no caso brasileiro, em que chegou a existir uma evolução produtiva e uma articulação entre os departamentos, mas que nunca rompeu com a dependência externa de mão de obra qualificada e certas máquinas).

No tratamento de Aglietta (que se debruçou sobre a história econômica dos Estados Unidos, particularmente) sobre o fordismo, em primeiro lugar, fica clara a atuação deste como modo de acumulação:

O fordismo é, assim, o princípio de uma articulação entre processo de produção e modo de consumo, que constitui a produção em massa que é o conteúdo específico da universalização do trabalho assalariado. O processo de trabalho característico do fordismo é a produção em linha de montagem semiautomática. Esse tipo particular de processo de trabalho foi estabelecido nos Estados Unidos a partir da década de 1920, especialmente para bens de consumo de massa produzidos em longos períodos de produção, e posteriormente estendido para a produção de componentes intermediários padronizados para a fabricação desses meios de consumo. (AGLIETTA, 2000, p. 117)

A utilização do fordismo parece se dar justamente porque a produção em massa (característica mais alardeada das fábricas de Detroit) é o elo entre todos os outros elementos combinados. Aglietta considera o fordismo (modo de consumo, de produção e de universalização do salário) como o corolário do regime de acumulação que vigeu a partir dos anos 1920 nos Estados Unidos. Em que pese essas ligeiras diferenças, pode-se dizer que a seguinte determinação resume bem o que comporta o conceito de fordismo: "produção em massa combinada com o apoio das instituições ao consumo de massa, incluindo um sistema de acordo coletivo que generalizou o compromisso de classe de relativos altos e crescentes salário em troca de paz laboral" (VIDAL, 2016, p. 284).

Para rastrear as origens desse problema no processo de trabalho, é preciso retomar algumas considerações do próprio Aglietta na caracterização dos regimes de acumulação que podem se caracterizar em extensivos e intensivos. Nas palavras de um comentador:

O regime de acumulação extensivo caracteriza um período histórico durante o qual (de acordo com Aglietta) predomina a extração de mais-valor absoluto. Fordismo ou o regime intensivo, por outro lado, exemplifica a produção de mais-valor relativo (DAVIS, 1978, p. 214).

Para Aglietta, há certa correspondência, portanto, entre os regimes de acumulação e as formas predominantes de extração do mais-valor no período daquele determinado regime. Assim, o período que se estende até o início do século XX se caracteriza por um regime de acumulação extensivo; e o período posterior à década de 1920, trata-se da maturação 
do regime fordista, que se difunde a partir do final dos anos 1940, como regime de acumulação intensivo.

Esta relação entre mais-valor absoluto e extensão; e mais-valor relativo e intensificação deve ser considerada, primeiramente. A discussão acerca da extração do mais valor nas formas absoluta e relativa, deve ser retomada no próprio Marx. Em suma, entende-se que o

mais-valor obtido pelo prolongamento da jornada de trabalho chamo de mais-valor absoluto; o mais-valor que, ao contrário, deriva da redução do tempo de trabalho necessário e da correspondente alteração na proporção entre as duas partes da jornada de trabalho chamo de mais-valor relativo (MARX, 2013, p. 390).

Pode-se dizer que, na medida em que o absoluto decorre da extensão do tempo de trabalho, por isso possui limitações pelas próprias condições físicas dos trabalhadores, o relativo está ligado ao aumento da força produtiva (meios de trabalho, materiais úteis à produção, dentre outras coisas) e faz com que a produtividade seja então aumentada sem que a jornada de trabalho seja também aumentada, reduzindo o tempo de trabalho necessário. Maior produção de mercadorias em um menor tempo de trabalho faz com que as mercadorias acumulem menor valor unitário e quando este processo de difunde por vários setores, o próprio valor da força de trabalho é reduzido, uma vez que ele corresponde ao valor dos bens que os trabalhadores necessitam para sobreviver. Em termos simples, com o mais-valor relativo permite maior extração de mais-valor pelo barateamento da força de trabalho.

O mais-valor absoluto preponderou durante os momentos mais primitivos do capitalismo, em que as relações de produção ainda possuíam resquícios de modos de produção anteriores (e ainda pode preponderar em setores com nível técnico mais regredido). Com o avanço do processo de acumulação e a inserção de inovações tecnológicas o mais-valor-relativo passou a preponderar. Mas essa preponderância não é significa a exclusão de outro. Na grande indústria, quando prepondera o mais-valor relativo, por exemplo, pode haver também o aumento do mais-valor absoluto com a eliminação dos poros no processo produtivo, devido ao ritmo imprimido pelo sistema de máquinas.

Mas a questão é que, em Aglietta, o determinante do mais-valor relativo é a intensificação. Marx mostra que esta não é uma relação tão automática. O autor mostra como o aumento da intensificação do trabalho pode não representar um rebaixamento dos salários, como é comum ao mais-valor relativo

A jornada de trabalho mais intensiva se incorpora em mais produtos do que a jornada menos intensiva de igual número de horas. Com uma força produtiva aumentada, a mesma jornada de trabalho fornece mais produtos. No último caso, porém, o 
valor do produto singular cai pelo fato de custar menos trabalho que antes; no primeiro caso, ele se mantém inalterado porque o produto custa a mesma quantidade de trabalho de antes. $\mathrm{O}$ número de produtos aumenta, aqui, sem que caia seu preço (MARX, 2013, pp. 591-2).

É fundamental perceber que mais-valor relativo não é sinônimo de intensificação do trabalho. A intensificação pode resultar no aumento da produtividade, mas, não sendo acompanhada de um aumento das forças produtivas, pode não significar o rebaixamento do valor da força de trabalho. Não é a intensificação condição necessária para a extração de mais-valor relativo, simplesmente porque a intensificação pode não significar a redução do valor da força de trabalho.

Acerca desse problema da intensificação, seguindo as linhas de Marx, Davis (1978) oferece uma resolução bastante pertinente ao que diz o autor alemão. Segundo Davis, para Marx, quando um novo grau de intensificação do trabalho é encetado na produção, primeiramente o seu efeito está mais localizado na compressão da jornada de trabalho e na eliminação dos poros, ocorrendo um aumento na quantidade de trabalho convertida na mercadoria. Portanto, atua a intensificação nesse momento como forma do mais-valor absoluto, portanto. Contudo, por outro lado, à medida que esse padrão de intensificação se torna mais geral, há uma recalibração e aquela eliminação dos poros deixa de ser um adicional e se torna o padrão. Nesse momento, a intensificação passa a atuar como forma de extração do mais-valor relativo, com uma jornada de trabalho mais intensiva. Isso não muda o que já foi exposto anteriormente, mas reforça o ponto de Marx quanto ao papel da intensificação do trabalho (pode ser grandeza intensiva ou extensiva).

Acompanhando então a diferenciação mais exata entre um regime de acumulação extensivo e intensivo, pode-se ler que o primeiro

é aquele em que o mais-valor relativo é obtido pela transformação da organização do trabalho; o modo de vida tradicional pode persistir ou ser destruído; (...) O desenvolvimento combinado dos dois departamentos de produção é alcançado apenas com dificuldade, o ritmo de acumulação encontra obstáculos recorrentes (AGLIETTA, 2000, p. 70)

Cabe salientar o acento que o autor francês dá para as mudanças na organização do trabalho como propulsão para o aumento da extração do mais-valor. Ou seja, no modo de regulação extensivo o autor sequer destaca o papel do revolucionamento tecnológico. O que se nota nesta argumentação é que o que Aglietta caracteriza como regime de acumulação extensivo está muito próximo do que Marx determina para a manufatura. É o que se verifica comparando esta elaboração com a descrição de Marx para a manufatura, tem-se que 
A força produtiva aumentada se deve aqui ou ao dispêndio crescente de força de trabalho num dado período de tempo portanto, à intensidade crescente do trabalho -, ou ao decréscimo do consumo improdutivo de força de trabalho. $\mathrm{O}$ excesso de dispêndio de força exigido em cada passagem do repouso ao movimento é compensado pela duração maior da velocidade normal, depois de esta ter sido alcançada (MARX, 2013, p. 415).

Fica evidente que Marx não fala sequer de algum desenvolvimento do sistema de máquinas para a obtenção de um avanço produtivo no período da manufatura. Maior produtividade se obtém através do melhor aproveitamento da força de trabalho durante o tempo de trabalho, aumentando, por exemplo, a velocidade e a eficiência dos movimentos. $\mathrm{Ou}$ seja, Marx também está falando de aumento da produtividade (intensidade, decréscimo do tempo improdutivo) por meio do aperfeiçoamento da organização do trabalho. O sistema de máquinas ainda não está posto. O regime de acumulação extensivo está próximo disso, mas não é a mesma coisa, uma vez que Aglietta simplesmente menciona o mais-valor absoluto como elemento distintivo. Para Marx, o que caracteriza a manufatura e o princípio subjetivo, a divisão do trabalho.

Por conseguinte, cabe considerar, finalmente, as considerações do francês para análise do regime de acumulação intensivo

O regime predominantemente intensivo de acumulação cria um novo modo de vida para a classe assalariada ao estabelecer uma lógica que opera sobre a totalidade do tempo e espaço ocupado ou atravessado por seus indivíduos na vida cotidiana. (...) $\mathrm{O}$ regime intensivo de acumulação realiza uma integração dos dois departamentos de produção que possibilita um ritmo muito mais regular de acumulação e um aumento muito mais rápido na taxa de mais-valia (AGLIETTA, 2000, p. 71).

O regime intensivo se trata de uma articulação entre produção e consumo tal que a integração entre os dois departamentos caminha de forma tão harmoniosa, que há uma aceleração no processo de acumulação. A linha de montagem semiautomática, ao se alastrar por ambos departamentos e uniformizar mais o processo de trabalho "é o processo de trabalho mais adequado para o mais-valor relativo" (AGLIETTA, 2000, p. 119). O fordismo é o elemento central de universalização desta extração do mais-valor relativo.

Analisando a argumentação do autor acerca do taylorismo e do fordismo, é possível entender que ambos estão assentados sob abstrato princípio da mecanização, que possui uma função muito clara: "Ao transferir as características qualitativas de trabalho para a máquina, a mecanização reduz o trabalho a um ciclo de movimentos repetitivos" 
(AGLIETTA, 2000, p. 113). Isto está alinhado exatamente com o que Marx definia para a grande indústria, como é possível acompanhar em Marx:

A partir do momento em que a máquina de trabalho executa todos os movimentos necessários ao processamento da matériaprima sem precisar da ajuda do homem, mas apenas de sua assistência, temos um sistema automático de maquinaria, capaz de ser continuamente melhorado em seus detalhes (MARX, 2013, pp. 454-5).

Assim, a grande indústria demarca uma mudança fundamental em relação à manufatura: o desprendimento da divisão do trabalho em favor do sistema de máquinas. Demarca-se assim, como mostrou Moraes Neto (1989), que Aglietta encontra no princípio básico do taylorismo, a mecanização (que para o francês também traduz o sistema de máquinas), as características fundamentais para a grande indústria ${ }^{2}$. Retém-se que os autores regulacionistas, como Aglietta, entendem que a grande indústria já estava generalizada ao final do século XIX, mas foi possível ver também que o sistema de máquinas não é o que determina a transição para o regime de acumulação intensivo, mas sim a preponderância do mais-valor relativo. Por isto, coisas diferentes se confundem: formas de extração do mais valor com a mudança na base técnica. Logicamente, o fordismo simplesmente se coloca como um desdobramento da grande indústria

O fordismo desenvolveu ainda mais a mecanização do trabalho, aumentou a intensidade do trabalho, radicalizou a separação entre trabalho manual e mental, sujeitou rigorosamente os trabalhadores à lei da acumulação e transformou o progresso científico em um poder que serve à expansão uniforme do valor. (AGLIETTA, 2000, p. 113).

E aqui se concretiza aquela indicação de que com a concreção do fordismo, torna-se generalizada a extração do mais-valor relativo, não restando dúvidas de que, para o autor, o que caracteriza o fordismo é o sistema de máquinas. Isto fica mais evidente quando o autor sublinha a própria esteira se coloca como a grande inovação do fordismo "Ele representou uma mutação das forças de produção que reduziam consideravelmente o tempo necessário para a transferência e manipulação de objetos que eram frequentemente pesados e difíceis de mover" (AGLIETTA, 2000, p. 118). Justificando da seguinte maneira:

a fixação de trabalhadores em empregos cujas posições eram rigorosamente determinadas pela configuração do sistema de máquinas. $\mathrm{O}$ trabalhador individual perdeu assim todo $\mathrm{o}$ controle sobre seu ritmo de trabalho. O fluxo linear contínuo proibia a formação de estoques intermediários entre os trabalhos e submetia o ritmo coletivo ao movimento uniforme do sistema da máquina. Nesse modo de organização, os

2 Coriat (1982) entende que a grande indústria se articulava com o taylorismo pelo fato de o último representar a aplicação da ciência à organização do trabalho. 
trabalhadores são incapazes de colocar qualquer resistência individual à imposição da norma de saída, uma vez que a autonomia do trabalho foi totalmente abolida (AGLIETTA, 2000, p. 118).

Aglietta enxerga a principal consequência dessa suposta modificação da base técnica na própria atuação sobre trabalhador, a retirada do controle sobre a produção. O controle do processo do trabalhador individual é transferido ao conjunto de operários parcelados ${ }^{3}$. E isto caracteriza o principal impacto do fordismo sobre o trabalho. A questão é: a retirada do controle do trabalho sobre a produção pode caracterizar uma distinção efetiva entre diferentes relações de produção (que nas palavras de Aglietta se representaria entre o período do regime extensivo e intensivo)? Marx pôde contribuir para a resolução desta questão

A combinação não é uma relação que lhes pertence, nem é subsumida sob eles como um grupo unido (...). Com a transformação de sua capacidade de trabalho em o que é meramente uma função de parte do mecanismo completo, o todo dos quais forma a oficina, ele deixou completamente de ser o produtor de uma mercadoria. Ele é apenas o produtor de uma operação unilateral, que em geral produz algo unicamente em conexão com todo o mecanismo que forma a oficina (...). Assim, ele é agora subsumido sob a produção capitalista, agora está sob o controle do capital, não mais porque ele não tem os meios de trabalho, mas por causa de sua própria capacidade de trabalho, a natureza e a maneira de seu trabalho (MARX, 2010, pp. 27980)

Nesta passagem, Marx se refere à subsunção real do trabalho sob a manufatura moderna (uma vez que não é possível sob a cooperação simples, tampouco sob a manufatura menos desenvolvida). Para Aglietta, nas palavras de Moraes Neto: “o fordismo inaugura a fase histórica da submissão real do trabalho ao capital” (1989, p. 72). Assim, o controle do processo de trabalho alheio ao trabalhador já estava dado antes mesmo do sistema de máquinas. Basta compreender que a divisão manufatureira do trabalho

cria, por meio da análise da atividade artesanal, da especificação dos instrumentos de trabalho, da formação dos trabalhadores parciais, de seu agrupamento e combinação num mecanismo total, a articulação qualitativa e a proporcionalidade quantitativa dos processos sociais de produção - portanto, uma

3 Isto pode até ter algum fundamentando na realidade concreta na medida em que o próprio Marx mostra que a subsunção real do trabalho se desenvolvia já na manufatura moderna. Contudo, é preciso demarcar que a subsunção real se confirma mesmo com a subordinação do capital inclusive das forças naturais ao processo de trabalho. Demove-se a dependência do trabalho qualificado, mas também das forças naturais. Seja como, for esta noção de Aglietta confirma o seu posicionamento do fordismo na grande indústria. 
determinada organização do trabalho social, desenvolvendo, assim, ao mesmo tempo, uma nova força produtiva social do trabalho (MARX, 2013, p. 438).

Logo, se um dos principais elementos que determinam o fordismo é o condicionamento do trabalhador ao controle do "mecanismo", o fordismo pode servir para definir tudo o que está entre a manufatura moderna e a grande indústria. Definir o fordismo como expressão da grande indústria tendo como principais aspectos a extração do mais-valor relativo e a subsunção real do trabalho não é inverídico, porém estes elementos não são o que determinada relação social de produção como manufatura ou grande indústria, mas sim o princípio ao qual ela está fundada: divisão do trabalho numa base técnica mais regredida; e sistema de máquinas numa base técnica mais evoluída.

Submetendo a análise à abordagem inflexionista, contudo, pode-se ver claramente que o fordismo está localizado na própria manufatura moderna, pois é constituído por elementos distintivos dessa relação social de produção:

trata o fordismo de fixar o trabalhador num determinado posto de trabalho, com as ferramentas especializadas para execução dos diferentes tipos de trabalho, e transportar através da esteira o objeto de trabalho em suas diferentes etapas de acabamento, até sua conformação como mercadoria. (MORAES NETO, 1988, pp. 36-7).

A esteira levava as peças ao trabalhador, mas este somente podia ajustá-las de modo a formar o veículo acionando suas ferramentas. As máquinas fordistas resolviam o problema da produção das peças, mas a montagem era manual. Portanto, os trabalhadores de fato não tinham o controle, mas ao mesmo tempo aquela mecanização não era completa. A divisão do trabalho ainda era o princípio vigente.

Para Aglietta, a evolução do processo de trabalho posterior à racionalização taylorista já está colocada nos termos da grande indústria, e isto pode decorrer das imprecisões do próprio autor quanto ao entendimento de outras categorias como o mais-valor relativo. $O$ francês procura construir uma esquematização teórica que não se confirma na realidade concreta, tampouco nos escritos de Marx. Joga luz para a forma de extração do mais-valor, para o controle do processo de trabalho, mas deixa de lado a mudança fundamental: a do princípio subjetivo para o princípio objetivo. É possível, dessa forma, levantar questionamentos como os de Moraes Neto (1988, p. 82): "como se pode entender que o fordismo apresenta limitações semelhantes em essência a uma forma de produção anterior à maquinaria (manufatura) e, ao mesmo tempo, constitua um desenvolvimento dessa mesma maquinaria?” 
Seja como for, é importante reter que, para os regulacionistas (incluindo Coriat e Lipietz), a inflexão técnica está dada com o fordismo, contudo os autores não compreendem como a esteira semiautomática não elimina a centralidade da divisão do trabalho. Inclusive, o grau abstrato das características centrais do fordismo (intensificação, controle, mecanização) não deixa de ser a base dos desdobramentos posteriores, como o pós-fordismo, determinado por outras abstrações como a flexibilidade. As condições de acompanhar qualquer inflexão estão obstruídas por este apego. Por outro lado, a tendência muito presente nos conceitos regulacionistas é a generalização, de tal modo que se ignora o fato de o fordismo estar localizado em um setor de desenvolvimento técnico mais retardado se comparado a outros. Em suma, há de fato uma incompatibilidade muito clara com as análises marxianas, o que não descarta alguns pontos em comum. A tentativa será mostrar como isso se apresenta nas análises do caso brasileiro.

\section{Base técnica e processo de trabalho na indústria automotriz brasileira}

A teoria da regulação encontrou ressonâncias no Brasil em elaborações teóricas que partiram de estudos históricos, sobretudo nos anos 1980, e tentaram dar conta das mudanças encetadas pela aplicação da automação na produção de veículos automotores. Por outro lado, essas análises, inspiradas nos autores franceses, também tentavam conectar o desenvolvimento de um fordismo brasileiro com aspectos macroeconômicos. A similaridade com a determinação de Aglietta do fordismo é evidente:

racionalização taylorista do trabalho: profunda divisão - tanto horizontal (parcelamento das tarefas) quanto vertical (separação entre concepção e execução) - e especialização do trabalho; desenvolvimento da mecanização através de equipamentos altamente especializados; produção em massa de bens com elevado grau de padronização; a norma fordista de salários: relativamente elevados e crescentes - incorporando ganhos de produtividade - para compensar o tipo de processo de trabalho predominante (FERREIRA, 1993, p. 9)

A partir desse conjunto de fatores consolidados nas grandes economias, esses autores lançaram o olhar para a maneira como esses elementos se concretizavam, no Brasil, tal e qual nos casos clássicos. Não é incomum que se encontre nos autores uma compreensão em dois níveis "em nível de planta industrial (para se referir ao processo de trabalho) quanto em nível de sociedade (para se referir ao que a escola regulacionista chama de um regime de acumulação)" (CARVALHO; SCHMITZ, 1990, p. 148). 
A tese fundamental, muito discutida em Coriat e Saboia (1989), é de que no Brasil (à luz de Lipietz e seu fordismo periférico), durante o período que seguiu do pós-guerra até a década de 1980, houve um desenvolvimento maior da indústria de bens de consumo, incapaz de estabelecer uma relação com a indústria de bens de capital de modo a impulsionar toda a indústria, com o emprego massivo de mão de obra proveniente dos trabalhadores que vinham do campo para as cidades. $\mathrm{O}$ trabalho, fundamentado na baixa qualificação, era empregado com altos níveis de rotatividade, o que contribuía para que não se atingissem os "níveis salariais fordicizados" dos países mais desenvolvidos, elemento que inclusive foi apontado como razão para o retardo técnico da indústria nacional. Tampouco havia o que poderia se considerar o "estadoprovidência” no mesmo nível daqueles países, por esta razão, os autores caracterizam este conjunto de elementos como fordismo restrito (CORIAT; SABOIA, 1989; FERREIRA; FERREIRA, 2015).

Em resumo, pode-se dizer que o desenvolvimento industrial no Brasil

\begin{abstract}
foi voltado para o mercado interno e baseado em um aumento significativo da taxa de investimento para o setor produtor de bens de capital. No entanto, e este é um fato amplamente conhecido, este regime de produtividade foi acompanhado por um regime de demanda que não corresponde à norma salarial fordista, nem a um estado de bem-estar social, nem ao consumo de massa. (FERREIRA; FERREIRA, 2015, p. 20).
\end{abstract}

Encaminhando mais diretamente para a questão do fordismo no processo de trabalho, é preciso dizer que os autores desta linha desenvolveram pesquisas em plantas industriais da indústria automobilística procurando verificar em que medida o grau de automação atingido era suficiente para superar a norma fordista, predominante até então, encetando uma transição para o pós-fordismo. Os autores compreendem, consequentemente, que é exatamente com a inserção da automação que ocorre a principal mudança no processo de trabalho da indústria nacional. E essas mudanças ocorreriam, como está contido em Aglietta, culminando na organização pós-fordista, assim caracterizada:

distribuir o trabalho não mais em postos individuais e tarefas parcelares, mas em "ilhas" de trabalhadores, em pequenos grupos gerando um conjunto homogêneo de tarefas; quebrar o caráter unidimensional das linhas de montagem e de fabricação, no sentido de conceber a oficina como uma rede de minilinhas entre as quais o produto circula segundo trajetórias que se tornaram complexas; enfim, substituir o transportador que se movimenta numa cadência fixa por veículos que se movem sobre uma rede, em cadências flexíveis (...). Em suma, passa-se das linhas unidimensionais a cadência rígida, para organizações 
multidimensionais em rede e a cadências flexíveis (FERREIRA, 1993, p. 18)

Como esta descrição não privilegia a mudança na relação social de produção mesma (como a transição da manufatura para a grande indústria), a caracterização se basta na descrição de novos arranjos organizacionais em termos muito abstratos. A mudança descrita oferece uma nova forma de organização da produção se for comparada com o fordismo clássico. Mas não é uma mudança que necessariamente caracteriza uma nova relação produtiva, justamente porque os autores optam por categorias que não capturam tal mudança. $O$ pós-fordismo não avalia em que medida a entrada da automação enceta mudanças qualitativas no processo de trabalho que superem o fordismo. $\mathrm{O}$ processo acima descrito, por exemplo, refere-se a mudanças organizativas, muitas delas ligadas ao toyotismo, que como mostrou Moraes Neto (2003), não foi produto de uma inovação técnica que tivesse rompido com o fordismo, mas de arranjos que permitiram uma extensão da manufatura moderna (divisão do trabalho e utilização reduzida de maquinaria). Por outro lado, a automação e a flexibilização, como conceitos centrais não poderiam ser sequer úteis para determinar um padrão técnico, pois a própria robótica não está generalizada em todos os setores, como mostraram Katz; Coggiola (1996). Estas inovações organizativas, que não tratam do aspecto técnico, reduzidas a estes conceitos abstratos fazem com que a mudança na base técnica, que traz implicações para a organização do trabalho, seja ignorada. Assim, o fordismo se coloca como uma categoria perene, reanimado por ajustes organizacionais. $\mathrm{O}$ caso concreto mostra que o fordismo é uma expressão da manufatura moderna, portanto ele pode ser superado na medida em que a inserção das máquinas demova a dependência da divisão do trabalho em todo o processo produtivo de veículos ou outros bens.

É preciso se ater à qualidade que a introdução da automação enceta no processo de trabalho. Para os autores, é evidente o impacto da automação no processo de trabalho da indústria automotriz nos países mais avançados. Segundo eles, "a automação programável está levando a indústria automobilística a um novo estágio, onde a força de trabalho não é mais o apêndice da máquina. A principal tarefa dos trabalhadores é monitorar a maquinaria e fazer manutenção" (CARVALHO; SCHMITZ, 1990, p. 149). Isto quer dizer que ocorre "um afastamento de uma situação em que a maioria dos trabalhadores está ocupada em manusear ou processar diretamente os produtos para uma na qual eles estão empenhados em preparar e monitorar equipamentos ou intervir no fluxo de produção quando aparecem problemas" (CARVALHO; SCHMITZ, 1990, p. 150). Os autores descrevem assim como a automação, no interior 
do setor metalomecânico, faz com que o processo de trabalho passe a ser levado pelo sistema de máquinas propriamente. Logo, “a orientação fordista/taylorista de intensificação do trabalho é substituída por uma forte preocupação com a performance ideal das máquinas" (CARVALHO; SCHMITZ, 1990, p. 150). Analisando a argumentação, para os autores, o trabalho ser apêndice da máquina equivale a manusear diretamente o produto e resume o sistema fordista. Nessa definição já existem elementos contraditórios, pois o trabalho apendicizado à máquina se trata justamente do trabalho que supervisiona as máquinas, são características do sistema de máquinas, e não do fordismo. A substituição do trabalho apendicizado às máquinas pelo trabalho de supervisão das máquinas não pode existir, pois são a mesma coisa. Os autores enxergam um parâmetro de mudança que não existe na realidade concreta.

Ademais, no fordismo, "o ritmo do processo de trabalho não é uma propriedade técnica da esteira, mas sim algo a ser posto em discussão a cada momento pelo trabalhador coletivo" (MORAES NETO, 1989, pp. 367). Na grande indústria, as máquinas estabelecem o grau de atuação do trabalho e isto retira a necessidade de manuseio do produto ou qualquer outra atividade que implique a atuação direta do operário no processo de transformação, também é incompatível com o sistema fordista, que depende grandemente da força de trabalho na montagem dos veículos.

Analisando o caso concreto, os autores dizem que o caso brasileiro se trata de uma automação seletiva. O resultado é que "com a introdução da tecnologia de automação programável, a organização de trabalho fordista não foi posta de lado, mas reforçada nas fábricas estudadas" (CARVALHO; SCHMITZ, 1990, p. 148). O caráter dessa mudança no Brasil, na visão dos autores, não significou uma entrada no que seria o pós-fordismo, mas a sobrevivência das técnicas fordistas devido à introdução de uma automação restrita a alguns setores do processo produtivo da indústria mecânica. Prevalece. a intensificação e a padronização em detrimento da flexibilização.

De modo que é possível acompanhar o exemplo

$\mathrm{Na}$ indústria automobilística brasileira a automação programável foi adotada para substituir apenas aquelas funções de manufatura que ou são cruciais para a qualidade do produto ou constituem estrangulamentos no fluxo de produção. O grosso das operações de manufatura continua a ser manual (CARVALHO; SCHMITZ, 1990, p. 151)

Em quantidade, as operações seguem sendo manuais, mas eles mesmo reconhecem que algumas funções centrais estavam sendo automatizadas e isto pode ser indício de mudança. Seguindo a análise mais detalhada do processo de soldagem na indústria automobilística, tem-se que: 
Em comparação com os sistemas mais automatizados encontrados nos países avançados, o novo processo de produção das empresas brasileiras apresenta um menor nível de deslocamento direto dos operadores de soldagem. No entanto, esta substituição seletiva foi acompanhada por uma maior integração de todas as operações de soldagem, seja realizada por máquinas ou pessoas. Isto foi conseguido automatizando as operações de transferência. O movimento das peças a serem soldadas juntas está "nas mãos" dos controladores programáveis que sincronizam as operações a um grau sem precedentes. Assim, os trabalhos passaram a ter mais ritmo de máquina do que antes. Em suma, a característica básica do novo processo é o deslocamento do trabalho manual em certas operações estratégicas de soldagem e a integração da maioria dos trabalhos restantes em um sistema de transferência direcionado eletronicamente. Como resultado, o fordismo, em vez de ser superado, é intensificado (SCHIMITZ; CARVALHO, 1989, p. 101)

Os autores descrevem que o sistema de máquinas caminha para tomar conta de todo o processo de soldagem, tornando supérfluo o trabalho dependente das habilidades humanas. Todavia, o fato de o trabalho estar mais 'controlado' pelo sistema de máquinas faz com que os autores afirmem se estar diante de uma acentuação do fordismo. Isto fica ainda mais evidente quando se compara com a forma com que o processo era conduzido antes da implementação de novas tecnologias:

Especialmente em alguns estágios críticos, os trabalhadores têm que manipular grandes peças de metal pesado, soldá-los juntos usando equipamentos pesados em posições muito extenuantes. Fazer este trabalho requer muita força física e conhecer os detalhes de cada operação. Isso significa que há uma certa diversidade de tarefas de soldagem ao longo da linha convencional, mas também significa grande esforço físico e risco para a saúde (SCHIMITZ; CARVALHO, 1989, p. 101).

Tratava-se de um trabalho basicamente manual. $O$ processo de trabalho era inteiramente dependente das faculdades humanas e potencializado pelo aumento da divisão do trabalho. Limitações que são superadas pelo sistema de máquinas. Isto é, as máquinas emulam as faculdades humanas e tornam a divisão do trabalho simplesmente desnecessária: "A nova linha elimina as operações mais exigentes fisicamente. Na verdade, a automação estava concentrada nessas áreas, até porque a precisão e até a qualidade eram difíceis de alcançar com o método anterior" (SCHIMITZ; CARVALHO, 1989, p. 101). Mas essas mudanças, mesmo se mostrando importantes no processo de trabalho do caso estudado, são deixadas de lado em detrimento da permanência dos traços alegadamente fordistas. Para os autores, seguem os pontos que justificam a acentuam o fordismo "A simplificação e padronização do 
trabalho (na nova linha analisada acima) é um pré-requisito para isso. $\mathrm{O}$ segundo é a subordinação da maioria dos trabalhos de soldagem ao ritmo da linha" (SCHIMITZ; CARVALHO, 1989, p. 102), perdem-se de vista os elementos que diferenciam um sistema de maquinaria de um sistema dependente das faculdades humanas. Exatamente como Aglietta, os brasileiros tomam o fordismo pela acentuação do controle que se expressa na extensão da desqualificação e da padronização das atividades, ou seja, por elementos abstratos que não identificam uma mudança. Tomados isoladamente, simplificação (através da desqualificação dos artesãos e supervisão da máquina), padronização e controle podem ser encontrados tanto a manufatura quanto na grande indústria, assim como a subordinação ao ritmo da linha (fábrica fordista ou uma indústria de processo contínuo). Vieira (1985) assevera inclusive que a robotização das plantas automotrizes engendrava uma padronização em grau nunca visto anteriormente, justamente pela dependência cada vez menor do trabalho vivo.

Analisando outros dados, é possível dizer que havia uma mudança da base técnica robusta em curso, com o emprego de máquinas cada vez mais complexas em outras partes do processo produtivo

$$
\begin{aligned}
& \text { A estampagem nesta nova fábrica é totalmente automatizada. } \\
& \text { Três operários operam a Komatsu Transfer Press. Aquele que } \\
& \text { está no controle da máquina era anteriormente um operador de } \\
& \text { máquina e recebeu dois meses de treinamento antes de se } \\
& \text { tornar um operador de prensa no novo equipamento. Seu } \\
& \text { salário não mudou. Dois outros homens trabalham na parte de } \\
& \text { trás do equipamento, empilhando peças estampadas. O novo } \\
& \text { equipamento produz uma grande economia de mão de obra. Por } \\
& \text { exemplo, na produção do painel interno para o Escort, } 14 \text { peças } \\
& \text { são produzidas por minuto por três trabalhadores (com } \\
& \text { capacidade total seriam 19), em comparação com uma linha } \\
& \text { convencional onde metade dessa produção seria alcançada e } 12 \\
& \text { os trabalhadores seriam obrigados a produzir a mesma peça } \\
& \text { (SILVA, 1988, p. 162). }
\end{aligned}
$$

Esta é a descrição do processo de estamparia na Ford do Brasil no mesmo período avaliado e o que se mostra é que a automação seguia um padrão determinado pelo tipo de produto. Os carros mais avançados tinham a produção mais automatizada, inclusive a própria Ford já utilizava robôs na linha de produção, na montagem desses veículos (SILVA, 1988). Assim, "Montar os modelos mais antigos é muito mais trabalhoso do que a loja de acompanhantes. Pegando as peças estampadas, juntando-as, segurando-as no lugar e aplicando as nadadeiras, tudo é feito manualmente" (SILVA, 1988, p. 170).

Outros dados apontados pelos autores apontam como o sistema de máquinas se solidificou naquela realidade: "o número absoluto de 
trabalhadores manuais diminuiu 20\% entre 1984 e 1986, um período durante o qual os níveis gerais de emprego estavam se recuperando" (CARVALHO; SCHMITZ, 1990, p. 153). Ou ainda, "a importância estratégica dos trabalhadores de manutenção está crescendo, e o conteúdo das suas funções está sendo reforçado no novo processo de trabalho" (CARVALHO; SCHMITZ, 1990, p. 153). Em razão do fato de considerarem o fordismo pelas abstrações padronização, intensificação e desqualificação, os autores deixam de perceber que há, na realidade, uma mudança marcante no processo de trabalho, que apesar de manterem as características por eles apontadas, tendem a romper com o fordismo, por levarem importantes partes do processo produtivo ao sistema de máquinas.

Se se tomar este processo de mudança gradual, é claro que permanecem a padronização e a simplificação das funções, dentre outras características, mas radicalmente, percebe-se que havia um processo de perda gradual de espaço da manufatura para a grande indústria (que no setor metalomecânico era representada mais fortemente pelo emprego de robôs). A divisão do trabalho cedia espaço para o sistema de máquinas, e esta mudança representava uma inflexão evidente no processo de trabalho. A década de 1980 fez esse processo ficar um pouco mais vagaroso por conta de crises que comprometeram a venda de veículos internamente e para exportação. Contudo, se o horizonte se apresentava amigável à grande indústria o movimento era de rompimento com o fordismo e a manufatura, não o seu recrudescimento.

\section{Considerações finais}

Do exposto, pôde-se ver que o conceito de fordismo, na tradição regulacionista, que legou maior influência, se constitui por uma série de propriedades do processo de trabalho que se reproduzem pelas diversas formas de relação de produção por serem muito gerais (simplificação, padronização, controle, dentre outras). Tomando o fordismo por estes conceitos, é possível entender que ele nunca se dissolveria, não importa a direção para a qual as mudanças apontem, como pôde se ver nos exemplos estudados. As categorias marxianas, por outro lado, denotam relações de produção específicas e, por isto, não reproduzem aquelas imprecisões. Elas denotam a mudança que transforma toda a dinâmica do processo de trabalho (a divisão do trabalho para o sistema de máquinas, no caso da manufatura para a grande indústria), o que se reflete na acumulação e nos efeitos sobre a luta de classes, sem que seja necessário ao mesmo tempo o apelo ao institucionalismo. 
Considera-se que a abordagem inflexionista possui um potencial importante para investigar a transformação industrial no Brasil a partir da averiguação dos casos concretos, considerando as especificidades de desenvolvimentos distintos entre os setores e também forças que podem acelerar ou refrear o processo de inflexão (como crises, políticas de estado, a luta de classes). O próprio setor automotivo, dado seu atraso em relação a outros mais precoces como o têxtil (alvo de análise do próprio Marx), como se viu, apresenta um processo de trabalho bastante fragmentado em que as mudanças levam tempo para transformar todo o setor, poderia ser explicado mais precisamente pelas categorias marxianas.

\section{Referências bibliográficas}

AGLIETTA, Michel. A theory of capitalist regulation: The US experience. London: Verso, 2000.

ALVES, Giovanni. Trabalho e subjetividade: o espírito do toyotismo na era do capitalismo manipulatório. São Paulo: Boitempo, 2011.

ANTUNES, Ricardo. O privilégio da servidão. São Paulo: Boitempo. 2018. CARVALHO, Ruy de Quadros; SCHMITZ, Hubert. O fordismo está vivo no Brasil. Novos Estudos, n. 27, 1990.

CORIAT, Benjamín. El taller y el cronómetro. Madrid: Siglo XXI, 1982.

; SABOIA, João. Regime de acumulação e relação salarial no

Brasil: processo de fordização forçada e contrariada. Ensaios FEE, Porto Alegre, 9(2) 1989.

DAVIS, Mike. "Fordism” in crisis: A review of Michel Aglietta's Régulation et crises: L'expérience des Etats-Unis. Review (Fernand Braudel Center), v. 2, n. 2 (Fall, 1978), pp. 207-69.

FARIA, José Henrique de. Poder, controle e gestão. Curitiba: Editora Juruá, 2017.

FERREIRA; Cândido Guerra. O fordismo, sua crise e o caso brasileiro. Texto para discussão n. 65. Belo horizonte: UFMG/Cedeplar, 1993.

; FERREIRA; José Arthur dos Santos. Peut-on parler du fordisme au Brésil? Crise, continuité et rupture du mode de regulation. Colloque International Recherche \& Régulation, Paris, 2015.

KABAT, Marina. La industria del calzado: cambios en la organización del trabajo entre 1880 e 1940. Desarrollo Económico, v. 47, n. 188, 2008.

KATZ, Cláudio; COGGIOLA, Osvaldo. Neoliberalismo ou crise do capital? São Paulo: Xamã, 1996.

LIPIETZ, Alain. Fordismo, fordismo periférico e metropolização. Ensaios FEE, Porto Alegre, 10(2), 1989.

MARX, Karl. O capital l. 1. São Paulo: Boitempo, 2013. 
; ENGELS, Friedrich. Collected works v. 30 1861-1863. London: Lawrence and Wishart, 2010.

MORAES NETO, Benedito Rodrigues de. A organização do trabalho sob o capitalismo e a "redoma de vidro". RAE-Revista de Administração de Empresas, [S.1.], v. 27, n. 4, pp. 19-30, out. 1987.

. Marx, Taylor, Ford: forças produtivas em discussão. São Paulo: Brasiliense, 1988.

. Século XX e trabalho industrial. São Paulo: Xamã, 2003,

SCHMITZ, Hubert; CARVALHO, Ruy de Quadros. Automation and labour in the Brazilian car industry. The Journal of development studies, 1989.

SILVA, Elizabeth Bortolaia. Labour and technology in the car industry: Ford strategies in Britain and Brazil. Tese (Doutorado) defendida no Imperial College of Science and Technology University of London, Londres, 1988.

VIDAL, Matt. Fordism and the golden age of atlantic capitalismo. In: EDGELL, Stephen; GOTTFRIED, Heidi; GRANTNER, Edward. The SAGE handbook of sociology of work and employment. Los Angeles: SAGE Reference, 2016.

VIEIRA, Darli Rodrigues. Funções da robótica no processo de acumulação: o caso do Brasil. Petrópolis: Vozes, 1985.

Como citar:

GUEDES, Leandro Theodoro. A crítica inflexionista das análises do fordismo brasileiro da década de 1980. Verinotio - Revista on-line de Filosofia e Ciências Humanas, Rio das Ostras, v. 25, n. 1, pp. 153-71, abr. 2019.

Data de envio: 6 fev. 2019

Data de aceite: 19 mar. 2019 